\title{
Erratum: Controlling the magnetic-field sensitivity of atomic-clock states by microwave dressing [Phys. Rev. A 90, 053416 (2014)]
}

\author{
L. Sárkány, P. Weiss, H. Hattermann, and J. Fortágh \\ (Received 22 June 2017; published 6 July 2017)
}

DOI: 10.1103/PhysRevA.96.019901

A typographical error in the article needs to be corrected. Equation (11) in the article should read

$$
\Delta E_{0,1} / \hbar=\omega_{0}+\left(\mu_{2}-\mu_{1}\right) B+6 \beta B^{2}-\Omega_{\text {dress }}^{2}\left(\frac{3}{\Delta_{1}(B)}+\frac{1 / 2}{\Delta_{2}(B)}+\frac{3 / 2}{\Delta_{3}(B)}\right) .
$$

We have ensured that all calculations in the article were made with the correct equation. Hence, all comparisons between experimental data and theory and the conclusions are unaffected by this.

The authors would like to thank Dr. Daniel Bothner for pointing out this error. 